\title{
Corresponding Member of the Russian Academy of Sciences M.G. Meshcheryakov (1910-1994) On the Centennial of His Birth
}

DOI: $10.1134 / \mathrm{S} 1063779610050072$

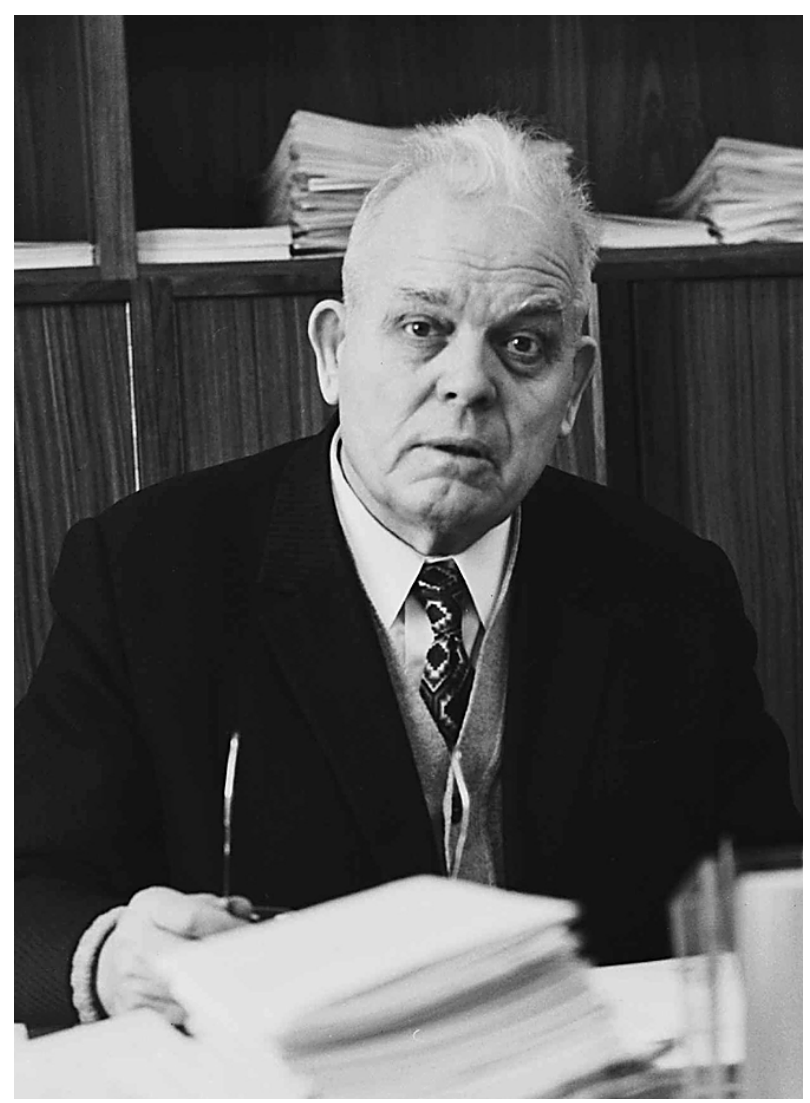

September 17, 2010, will mark 100 years since the birth of Mikhail Grigor'evich Meshcheryakov, a prominent experimental physicist, talented organizer of scientific research, two-time laureate of the State Prize of the Soviet Union, and corresponding member of the Soviet Academy of Sciences. Meshcheryakov was one of the Soviet scientists who took an active part in solving the atomic problem in the Soviet Union, led the construction of the world's largest proton accelerator (December 1949), and was behind the creation of the city of Dubna and the Joint Institute for Nuclear Research (JINR). In 1966 he headed work on organization of the new Laboratory of Computer Technology and Automation at the JINR. He was a professor at Moscow State University from 1958 on.

In different periods Meshcheryakov was a member of the Board of the Department of Physical and Mathematical Sciences of the Soviet Academy of Sciences and a member of the Editorial Boards of the journals Atomic Physics, Nuclear Physics, Journal of Experimental and Theoretical Physics, and Physics of Particles and Nuclei.

He was awarded three Orders of Lenin, the Order of the Red Banner of Labor, the Order of the Red Star, the Order of the Badge of Honor, and many medals, as well as orders and medals of the JINR member states. 